\title{
Coordination Training Model Innovation for Junior Futsal Players: Aiken's Validity
}

\author{
Yulvia Miftachurochmah ${ }^{1,{ }^{*}}$ Endang Rini Sukamti ${ }^{1}$ \\ ${ }^{I}$ Faculty of Sport Sciences, Universitas Negeri Yogyakarta, Yogyakarta, Indonesia \\ ${ }^{*}$ Corresponding author.Email: yulviamiftachurochmah.2020@student.uny.ac.id
}

\begin{abstract}
Coordination is one of the most critical elements for futsal players, especially for junior players. This study aimed to examine the content validity of the coordination training model for junior futsal players using a qualitative and quantitative approach. Four experts, two in the physical condition and two in futsal, joined this study as participants. The data were collected using the Delphi technique with a questionnaire scale of 1-5 as the instrument. The data obtained were then analyzed using Aiken's $\mathrm{V}$ formula, which helped test the content validity of the coordination training model. The study results showed that (1) the coordination training model has a $\mathrm{V}$ value of more than 0.880 , indicating that the coordination training model was valid and (2) the concept and operational coordination training model for junior futsal players had been arranged. In summary, the coordination training model has validity above the $\mathrm{V}$ table value, so it can be said that this training model was reliable and could be tested further. For this training model to be stronger, it is necessary to test the empirical validity and reliability of the retest test.
\end{abstract}

Keywords: Coordination, Futsal, Aiken's, Training, Innovation.

\section{INTRODUCTION}

Futsal is a swift and dynamic game with a relatively small field and almost no room for mistakes [1]. Therefore, in futsal, it is necessary to have a good physical condition of coordination. Another determination of futsal is a ball game played by teams of five people [2], which highly requires teamwork and eye-foot-hand coordination to move efficiently [3].

Coordination is a combined results of performance and quality of muscles, bones, and joints in producing effective and efficient motions or moves [4]. Coordination can also be defined as a person's ability to effectively integrate various movements into a single movement pattern [5]. Meanwhile, according to [6], coordination is a neuromuscular quality that allows a human's movements to be organized, regulated, and executed accurately, dynamically, and energyefficiently. In futsal, players need coordination skills to control the ball for as long as possible, monitor the movements of other players, and play compactly in a team [7]. Besides that, coordination is also needed in a movement without the ball, such as running, twisting, tackling, and guarding opponents-meanwhile, movements with the ball in futsal, including dribbling, passing, and shooting do need coordination as well. Players with good body coordination can easily carry out every movement whether it is with and without the ball [8].

Coordination in futsal is futsal players' ability to perform complex movements, either with the ball or without the ball, at a certain level of difficulty and be done quickly and efficiently [9]. For example, when shooting at the goal, the coordination between the eyes and feet to make shooting movements and the hand swing to support body balance are necessary so that the kick can be done well and aimed precisely towards the goal. Coaching coordination can facilitate the process of controlling and directing movement, build motor skills and variations of movement, and aid in adapting rapid changes in movement to respond to situations that suddenly come [10].

Futsal players must possess good coordination because they are required to perform very complex movements [11]. Futsal is one sport that needs to be coached from a junior age before giving complex trainings during peak performance. To achieve excellent and maximum performance, physical training, especially this coordination, should start from the junior age repeatedly, continuously, periodically according to 
the principles and norms of proper and good training in a structured program and regularly [12].

Technical and tactical training is more dominant in the futsal field, while coordination training is still monotonous. Based on the coach's experience, they have done it without considering the training's dose and impact. Good physical training will still pay attention to the characteristics or specificity of the sport [13] so that a coach is expected to be creative in determining the training program and model so that it fits the target. In addition, many coaches found that developing coordination training is not yet accompanied by systematic planning and training programs. They train on an experiential and intuitive basis only, and most of the time, they imitate success coaches and the physical training model of famous athletes trying out a training model with unknown effectiveness. As a result, many players experience fatigue, injury, and even a little overtraining. Physical training programs without being based on the correct training principles may harm the physical condition of athletes [14]. Coaches often do not immediately thoroughly evaluate why it happenedeven trying to find a scapegoat that the fault lies with the players themselves.

Content validity is a measure in which the content is an instrument that can be in the form of construction, or it can be described as a measuring tool for measuring sports activities [15] that has to be precisely built by considering its relevance, completeness, goals, and objectives [16]. Therefore, the validity test can be appropriately utilized to measure the validity of the content of the coordination training model in the futsal sport, especially for junior players.

Lack of research that focuses on bio-motor coordination in futsal, especially in junior players, made this study aimed to develop a model of coordination training for junior players in the futsal sport by determining the validity of its contents. It was hoped that the coordination training model developed by the researcher could be utilized as a reference for making a training program with a scientific basis to provide maximum performance.

\section{METHOD}

This mixed study combined qualitative and quantitative approaches to obtain complete and valid data $[17,18]$. Mixed methods are when an expert or researcher uses a combination of qualitative and quantitative research methods with one concept or when a study is carried out sequentially or simultaneously to examine research in-depth [19].

\subsection{Participans}

The participants in this study were four material experts. Two of them have qualifications of doctoral experts in the physical condition and sports evaluation, and two are sport practitioners in futsal who handle the junior futsal academy.

\subsection{Procedure}

This research has been done in three stages. The first stage was a qualitative approach using the literature reviews method with a narrative review type $[20,21]$ articles, journals, and textbooks related to the coordination training model, which was used to develop the coordination training model development. The second stage was a content validity test using the Delphi technique [15], where each expert did not meet when assessing the coordination training model in futsal. The third stage was a qualitative analysis of input from the previous expert judgment stage, then the results were analyzed for revision before the researchers handed them back to the experts for rechecking, and the process was done until it was wholly accepted without further improvement and the score has been given. Research instrument used in this research was a questionnaire with a rating scale of 1 to 5 with descriptions of very inappropriate, not feasible, quite feasible, feasible, and very feasible.

\subsection{Data Analysis}

To analyze the data in this study, the researchers used Aiken's V [22] with a significance level of 5\%. In this study, items were rated by four ratters on a scale of 1-5. According to Aiken's table, it can be valid if the minimum $\mathrm{V}$ value received is 0.880 . Aiken's $\mathrm{V}$ formula is as follows:

$V=\frac{\sum\left(r_{i}-l_{0}\right)}{[n(c-1)]}$

Information:

$\mathrm{V}=$ index of ratter agreement on item validity

$\mathrm{r}=$ number given by ratters

lo $=$ the lowest score of validity ( 1 for a scale of $1-5)$

$\mathrm{c}=$ the highest validity rating score $(5$ for a scale of 1 5)

$\mathrm{n}=$ the number of experts who do the assessment

\section{RESULT}

\subsection{Qualitative Analysis Result}

The qualitative analysis that used literature review techniques and expert judgment input resulted in a coordination training model for junior futsal players. This training model is recommended during the final general preparation into the particular initial period for 
futsal players in the 12-year age category (KU-12). Here are eight models of coordination trainings:

\subsubsection{Leadder Single Step with Passing and Control}

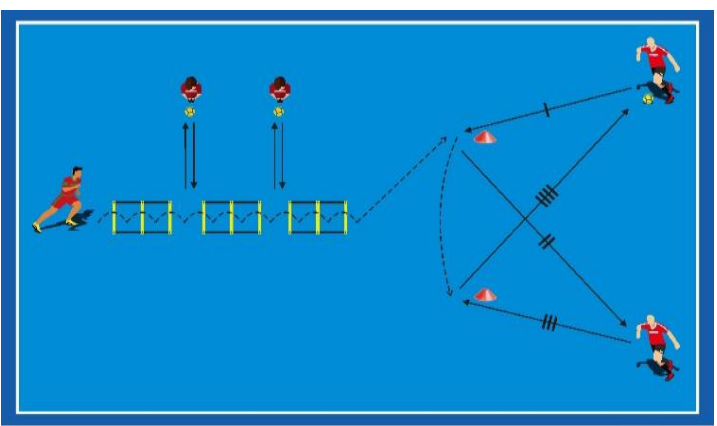

Figures 1. Leadder Single Step with Passing and Control

Learning unit: Integration coordination training using passing and control techniques.

Objectives: Enrich hand, foot, and eye movements and synchronizations, and emphasize the coordination training.

Number of Players: three players

Equipment: leader, marker, and ball

Drills Description:

a. Player A performs foot coordination with single steps, and every two steps, the player performs passing control with server players. Player A then runs to the marker to receive the ball from player $\mathrm{B}$ and pass it to player $\mathrm{C}$.

b. Player A moves to the next marker, then receives the ball from player $\mathrm{C}$ and then player $\mathrm{A}$ passes the ball to player B.

c. After becoming a server player, the server players take turns coordinating movements.

d. Create 2-3 spots to avoid queues.

e. Do it with a duration of $3 \times 5$ minutes. Every 5 minutes, the direction of running and the direction of passing can be changed

Implementation Evaluation:

a. Emphasis on enriching movement and coordination trainings.

b. Ignore the final results of the passing and control. It can be varied by doing the finishing.

\subsubsection{Leadder Double Step Integracy with Chipping}

Learning unit: Integration coordination training using the chipping technique

Objectives: Enrich hand, foot, and eye movements and synchronizations, and emphasize the coordination training.

Number of Players: three players

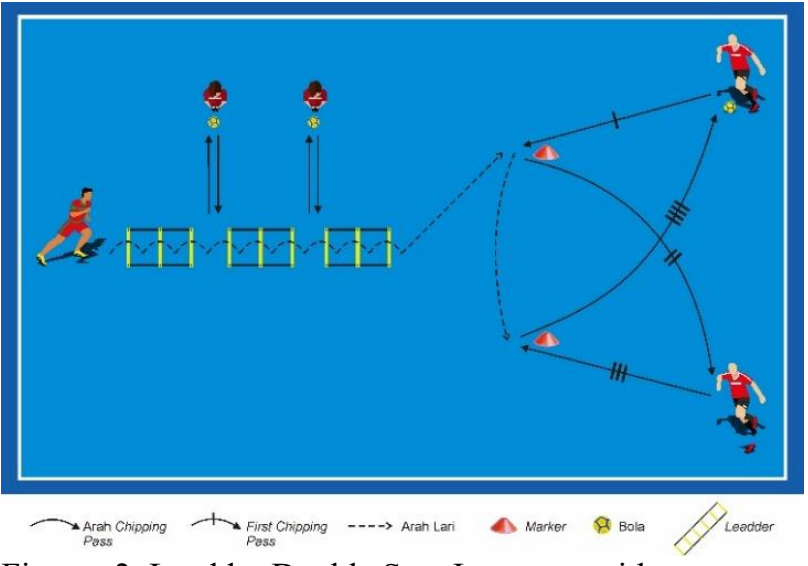

Figures 2. Leadder Double Step Integracy with Chipping

Equipment: leader, marker, and ball

Drills Description:

a. Player A performs foot coordination with double steps. Every time the player performs double steps, he/she then performs passing control with the server player, runs to the marker to receive the ball from player B, and performs chipping technique to player C.

b. Player A moves to the next marker, then receives the ball from player $\mathrm{C}$ and then player A performs chipping technique to player $\mathrm{B}$.

c. Create 2-3 spots to avoid queues.

d. Do it with a duration of $3 \times 5$ minutes. Every 5 minutes, the direction of running and the direction of passing can be changed.

Implementation Evaluation:

a. Emphasis on enriching movement and coordination trainings.

b. Ignore the final result of the engineering model.

\subsubsection{Leadder Lateral Steps Run Integrasi with Dribbling}

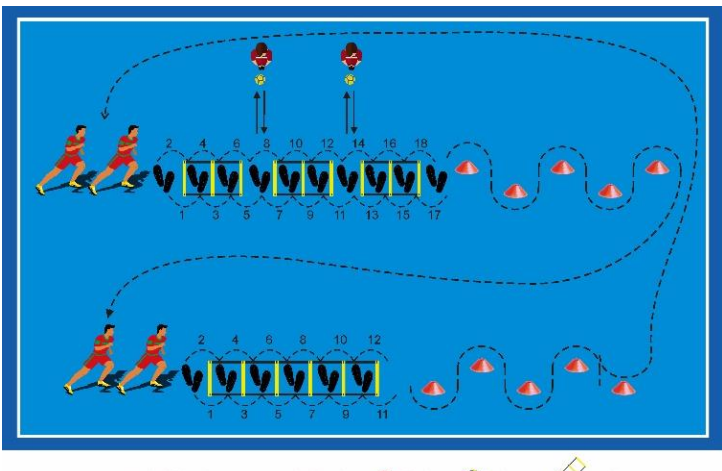

Figures 3. Leadder Lateral Steps Run Integrasi with Dribbling

Learning unit: Integration coordination training using dribbling.

Objectives: Enrich hand, foot, and eye movements and synchronizations, and emphasize the coordination training. 
Number of Players: four players

Equipment: leader, marker, and ball

Drills Description:

a. Players are divided into two teams for two practice spots

b. In the first spot, the players perform lateral steps run. With every two lateral steps run, they perform a passing control with the server player. They then do the zig-zag dribbling, pass the marker, and head to the second spot.

c. In the second spot, the players perform a coordinated movement of lateral steps run, then runs zig-zag to pass the marker, then run to the first spot after the last marker.

d. Do it in two sets, with 1 set of 10 repetitions. Implementation Evaluation:

a. Footsteps must be done correctly and precisely.

b. Emphasis on coordination training.

\subsubsection{Leadder Lateral In and Out Run Integrasi with $1 v 1$}

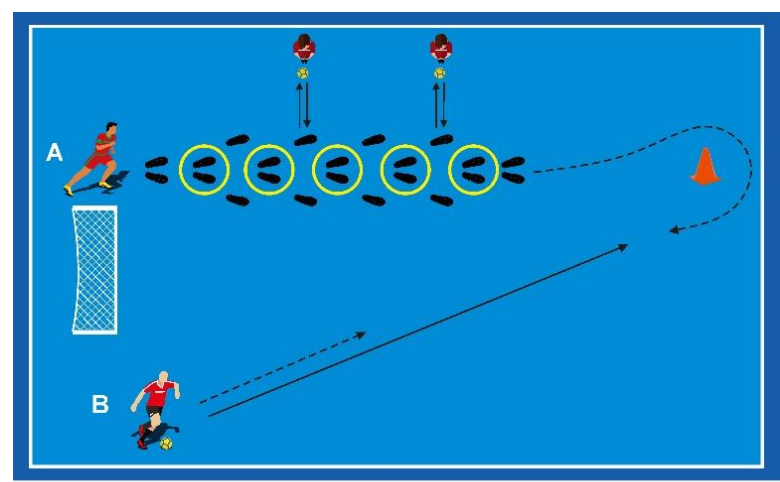

$\longrightarrow$ Arah Passing $--\rightarrow$ Arah Lari 1 Cone Bola Gawang Ring

Figures 4. Ladder Lateral In and Out Run Integrasi with $1 \mathrm{v} 1$

Learning unit: Integration coordination training using $1 \mathrm{v} 1$

Objectives: Enrich hand, foot, and eye synchronization, and cultivate competitive motivation. Number of Players: 2 players and two servers.

Equipment: leader, marker, and ball

Drills Description:

a. First, the players perform the in and out run. Every time the players perform it twice, they then do a passing control movement with the server player.

b. Next, player A gets the ball from player B, who will be the opponent.

c. Then player A takes the ball, passing the opponent's barrier, dribbling the ball, then shoots at the goal.

d. Player B tries to get the ball in possession of player A.

e. Do it in two sets, with 1 set of 10 repetitions.

Implementation Evaluation:

a. Footsteps must be done correctly and precisely.

b. Emphasis on coordination trainings.

\subsubsection{One Foot\&Right Hop with Dribbling}

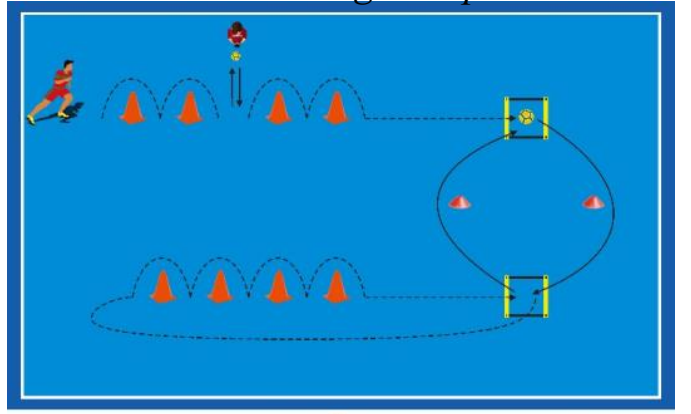

Figures 5 . One Foot \& Right Hop with Dribbling

Learning unit: Integration coordination training using dribbling

Objectives: Enrich hand, foot, and eye synchronization and grow motivation to practice.

Number of Players: one player and one server

Equipment: leader, marker, cone, and ball

Drills Description:

a. The player coordinates in the first spot by jumping over the cone using their right foot. Every time they jump, the player performs passing control with the server player and then runs to the box containing the ball.

b. Next, the player dribbles the ball passing the marker, goes to the next box, and then does coordination movements in the next spot by jumping over the cone using his/her left foot. Every time the player makes the jump twice, he/she does the passing control with the server player.

c. Furthermore, the player goes dribbling back to the first box.

d. Do it in two sets, with 1 set of 10 repetitions. Implementation Evaluation:

a. Footsteps must be done correctly and precisely.

b. Emphasis on coordination trainings.

\subsubsection{Two Foot Hops with Shooting}

Learning unit: Training coordination integration using shooting.

Objectives: Enrich hand, foot, and eye synchronization, and grow motivation to practice. Number of Players: two players and one server. Equipment: leader, marker, cone, and ball Drills Description:

a. Player A jumps over the cone with both feet. Every time the player jumps, the player does a passing control with the server player, then runs to change direction according to the marker that has been prepared.

b. The player then receives the ball from player B and shoots the ball into the goal with no goalkeeper.

c. Do it with a duration of $2 \times 5$ minutes. Every 5 minutes, change the direction of running to alternate when shooting the right and left feet.

Implementation Evaluation: 
a. Footsteps must be done correctly and precisely.

b. Emphasis on coordination trainings

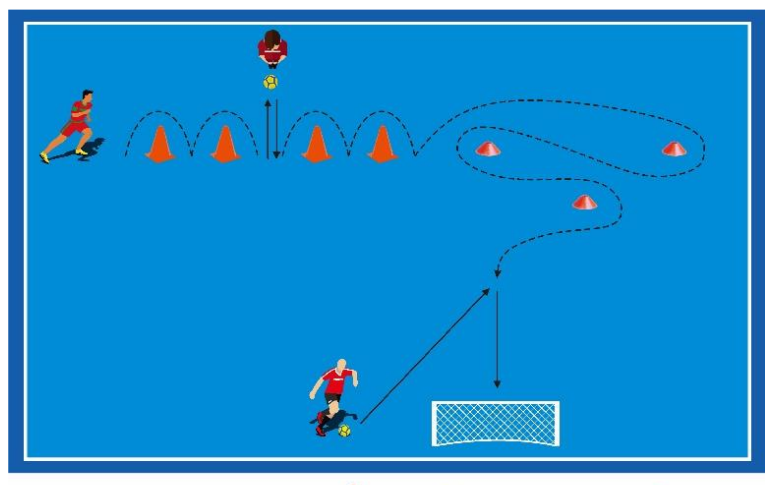

$\longrightarrow$ Arah Passing $\rightarrow-\rightarrow$ Aran Lai $\backslash$ cone Bola $\square$ Gavang $\triangle$ marter

Figures 6. Two Foot Hops with Shooting

\subsubsection{Zig-zag Run with $1 v 1$ and Shooting}

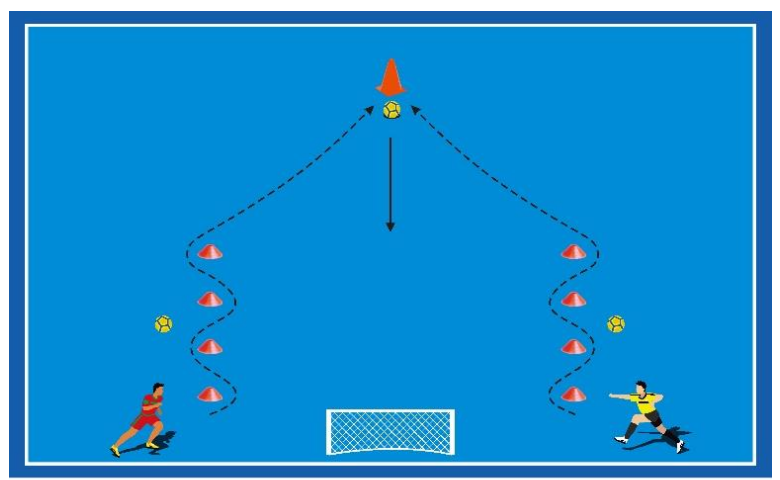

$\longrightarrow$ Arah Passing - --> Arah Lari 4 cone Bola Gawang Marker

Figures 7. Zig-zag Run with 1v1 and Shooting

Learning unit: 1v1 integration coordination training using shooting

Objectives: Enrich hand, foot, and eye synchronization, and cultivate competitive motivation. Number of Players: 2 players

Equipment: leader, cone, marker, and ball

Drills Description:

a. Players are divided into two groups by wearing different vest colours: one red player and one black player.

b. Prepare to carry out the training by doing ball feeling: touch the ball ten times.

c. Next, the players make a zig-zag motion, pass the marker, and then run towards the contested ball in the cone.

d. The player who first manages to hold the ball near the cone is the player who shoots at the goal. The goal has no goalkeeper. e. The winner is the group that scores the most goals every 5 minutes.

f. Do it with a duration of $2 \times 10$ minutes. Implementation Evaluation:

a. Footsteps must be done correctly and precisely.

b. Emphasis on coordination trainings.

\subsubsection{Combination Training Using Circuit System}

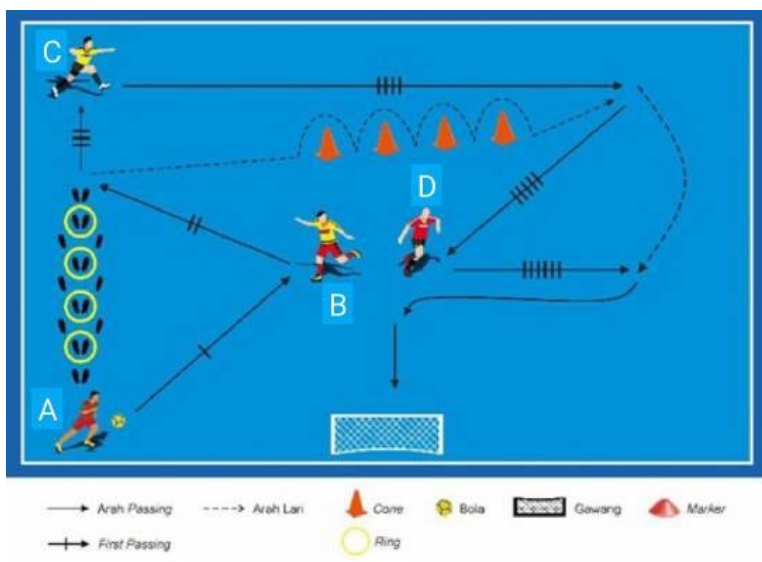

Figures 8. Combination Training Using Circuit System

Learning unit: Training coordination using the circuit system.

Objectives: To train children's coordination and cooperation skills.

Number of Players: four players

Equipment: leader, cone, marker, rings, and ball

Drills Description:

a. Player A does the passing to player B, then player A performs foot coordination and then receives the ball from player B to move the ball to player $\mathrm{C}$.

b. After passes the ball to player C, player A does the right and left feet coordination movement alternately, then rushes to get the ball from player $\mathrm{C}$, and does the passing to player $\mathrm{D}$.

c. Player D does the one-two passing to player A who performs movements, receives the ball from player D, dribbles towards the goal, and finishes.

d. Each child performs two sets alternately, with 1 set of 10 repetitions.

Implementation Evaluation:

a. Footsteps must be done correctly and precisely.

b. Emphasis on coordination trainings. 


\subsection{Content Validity Test Results}

\section{Table 1. Content Validity Results}

\begin{tabular}{|c|c|c|c|c|c|c|c|c|c|c|c|}
\hline \multirow{2}{*}{$\begin{array}{l}\overline{\mathrm{J}} \\
\bar{\Sigma}\end{array}$} & \multirow{2}{*}{$\underline{\Xi}$} & \multicolumn{4}{|c|}{ Evaluators } & \multirow{2}{*}{ s1 } & \multirow{2}{*}{ s2 } & \multirow{2}{*}{ s3 } & \multirow{2}{*}{ s4 } & \multirow{2}{*}{$\sum \mathbf{s}$} & \multirow{2}{*}{$\mathbf{V}$} \\
\hline & & I & II & III & IV & & & & & & \\
\hline 1 & \multirow{8}{*}{$\begin{array}{l}\text { I } \\
\text { I․ }\end{array}$} & 48 & 53 & 48 & 42 & 36 & 41 & 36 & 30 & 143 & 0,993 \\
\hline 2 & & 48 & 58 & 57 & 54 & 36 & 46 & 45 & 42 & 127 & 0,882 \\
\hline 3 & & 54 & 54 & 56 & 56 & 42 & 42 & 44 & 44 & 128 & 0,889 \\
\hline 4 & & 52 & 54 & 57 & 56 & 40 & 42 & 45 & 44 & 127 & 0,882 \\
\hline 5 & & 50 & 56 & 57 & 57 & 38 & 44 & 45 & 45 & 127 & 0,882 \\
\hline 6 & & 49 & 56 & 58 & 58 & 37 & 44 & 46 & 46 & 127 & 0,882 \\
\hline 7 & & 48 & 58 & 58 & 54 & 36 & 46 & 46 & 42 & 128 & 0,889 \\
\hline 8 & & 46 & 58 & 59 & 54 & 34 & 46 & 47 & 42 & 127 & 0,882 \\
\hline
\end{tabular}

Table 1 shows the Aiken's V values of training models 1 to 8 , with items 1 to 12 . According to the results shown in the table, it can be said that all the training models developed by the researcher are valid because the values of $\mathrm{V}$ are more than the Vtable.

\section{DISCUSSION}

Validity is one of the essential issues in the development process when preparing the training model [20]. Validity can illustrate the extent to which the development of a training model is genuinely appropriate and able to provide accurate information. Coordination is one of the crucial elements for athletes that help achieve maximum performance [23]. Meanwhile, futsal is a game that requires an effective and efficient motion to win the match [24]. Effective and efficient movements can be done when the players have good coordination. One's success in winning matches does not come solely from innate talent. Players have to train hard with the right program.

Futsal players at the junior, youth, adult, and professional levels have different characteristics. The development of junior futsal in Indonesia has shown progress, as evidenced by regulations or laws for junior players legalized by the Indonesian Futsal Federation (FFI) under the Indonesian Futsal Academy Association in 2020. The following movements mark futsal for children: basic movement, easy to understand, and fun. Futsal has the characteristics of moving in all directions, moving forward, backward, sideways with good acceleration and rapid change of direction [6]. Therefore, training programs for junior players must be designed by prioritizing multilateral trainings with coordination of foot and hand movements and adapted to these players' characteristics to prepare junior futsal players to have a perfect range of motion in the future.
The validity test results of all coordination training models produced $\mathrm{V}$ values above or greater than 0.880 . The values of $\mathrm{V}$, when compared to the value of the standard table compiled by Aiken [22], can be concluded to be valid using a rating scale of 1-5 and 4 raters. In other words, the coordination training model for junior futsal players has a reasonably high expert agreement.

\section{CONCLUSION}

Based on the results of this study, it can be inferred that the coordination training model for junior futsal players has reasonably high validity, with Aiken's V minimum standard of 0.880 . Therefore, this training model can be used or tested for coordination trainings for junior futsal players. For this training model to be stronger, it is necessary to test the empirical validity and reliability of the retest test.

\section{ACKNOWLEDGMENTS}

The author would like to thank Yogyakarta State University and those who have helped and contributed to this research to finish the article well.

\section{REFERENCES}

[1] V. Hermans, R. Engler, Futsal: Technique, tactics, training, Meyer \& Meyer Verlag, 2010.

[2] N. Naser, A. Ali, P. Macadam, "Physical and physiological demands of futsal," J. Exerc. Sci. Fit, 2017, vol. 15, pp. 76-80. DOI: https://doi.org/10.1016/j.jesf.2017.09.001.

[3] B. Travassos, D. Araújo, L. Vilar, T. McGarry, "Interpersonal coordination and ball dynamics in futsal (indoor football)," Hum. Mov. Sci, 2011.

DOI: https://doi.org/10.1016/j.humov.2011.04.003.

[4] N. Nur Ramadaniawan, "Anthropometrics and Physical Fitness Factors As Determinants of Futsal Dribbling and Passing Skills of Extracurricular Students Aged 12-15 Years," Int. J. Educ, 2018.

[5] B.C.M. Smits-Engelsman, L.D. Jelsma, G.D. Ferguson, The effect of exergames on functional strength, anaerobic fitness, balance and agility in children with and without motor coordination difficulties living in low-income communities, Hum. Mov. Sci, 2017, vol. 55, pp. 327-337.

[6] J. S. Blatter, Futsal - Coaching Manual, 2014.

[7] P. Silva, D. Chung, T. Carvalho, T. Cardoso, K. Davids, D. Araújo, J. Garganta, "Practice effects 
on intra-team synergies in football teams," Hum. Mov. Sci, 2016, vol. 46, pp. 39-51. DOI: https://doi.org/10.1016/j.humov.2015.11.017.

[8] H. Agras, C. Ferragut, J.A. Abraldes, "Match analysis in futsal: A systematic review," Int. J. Perform. Anal. Sport, 2016, vol. 16, pp. 652686.

DOI: https://doi.org/10.1080/24748668.2016.1186891 5.

[9] J.B. Farley, J. Stein, J.W.L. Keogh, C.T. Woods, N. Milne, The Relationship Between Physical Fitness Qualities and Sport-Specific Technical Skills in Female, Team-Based Ball Players: A Systematic Review, Sport. Med, 2020, vol. 6, pp. 1-20.

[10] H. Nascimento, C. Alvarez-peregrina, C. Martinez-perez, Á.S. Miguel, Vision in Futsal Players: Coordination and Reaction Time, 2021. https://doi.org/https://doi.org/10.3390/ijerph181 79069.

[11] J. Torres-Torrelo, D. Rodríguez-Rosell, J.J. González-Badillo, "Light-load maximal lifting velocity full squat training program improves important physical and skill characteristics in futsal players," J. Sports Sci, 2017, vol. 35, pp. 967-975.

[12] T.A. Shilko, G.A. Novikova, Physical development and fitness indices of junior female wushu competitors, Teor. i Prakt. Fiz. Kult, 2018 .

[13] D.L. Gill, L. Williams, E.J. Reifsteck, Psychological dynamics of sport and exercise, Human Kinetics, 2017.

[14] D. Memmert, K.A.P.M. Lemmink, J. Sampaio, "Current Approaches to Tactical Performance Analyses in Soccer Using Position Data," Sport. Med, 2017, vol. 47. DOI: https://doi.org/10.1007/s40279-016-0562-5.

[15] C.B. Terwee, C.A.C. Prinsen, A. Chiarotto, H.C.W. De Vet, M.J. Westerman, D.L. Patrick, J. Alonso, L.M. Bouter, L.B. Mokkink, "COSMIN standards and criteria for evaluating the content validity of health-related Patient-Reported Outcome Measures: a Delphi study," Qual Life Res, 2017, vol. 27, pp. 1159_1170.

[16] Q.N. Hong, P. Pluye, S. Fàbregues, G. Bartlett, F. Boardman, M. Cargo, P. Dagenais, M.P. Gagnon, F. Griffiths, B. Nicolau, A. O'Cathain, M.C. Rousseau, I. Vedel, "Improving the content validity of the mixed methods appraisal tool: a modified e-Delphi study", J. Clin. Epidemiol, 2019, vol. 111, pp. 49-59.e1. DOI: https://doi.org/10.1016/j.jclinepi.2019.03.008.

[17] J. Brannen, Mixing methods: Qualitative and quantitative research, Routledge, 2017.

[18] A. Petrovic, V. Koprivica, B. Bokan, "Quantitative, qualitative and mixed research in sport science: a methodological report," South African J. Res. Sport. Phys. Educ. Recreat, 2017, vol. 39, pp. 181-197.

[19] W.A. Edmonds, T.D. Kennedy, An applied guide to research designs: Quantitative, qualitative, and mixed methods, Sage Publications, 2016.

[20] H. Widodo, S. Nahimana, "REACTION TIME TEST INNOVATION OF TABLE TENNIS PERFORMANCE : AIKEN VALIDITY," 2021, vol. 18, pp. 7103-7110.

[21] D. Yudhistira, Tomoliyus, "Content validity of agility test in karate kumite category," Int. J. Hum. Mov. Sport. Sci, 2020, vol. 8, pp. 211216.

DOI: https://doi.org/10.13189/saj.2020.080508.

[22] L. Aiken, "Three Coefficients For Analyzing The Reliability And Validity Of Ratings," Educ. Psychol. Meas, 1985, vol. 45, pp 131-141.

[23] M. Mariana, C. Orlando, "Performance Criteria in Aerobic Gymnastics - Impact on the Sportive Training," Procedia - Soc. Behav. Sci, 2014, vol. 117, pp. 367-373.

[24] Y. Miftachurochmah, S. Nahimana, E.R. Sukamti, "Tactics Analysis of Attacking the Pansa FC Women's Futsal Team Yogyakarta, Indonesia," Int. J. Hum. Mov. Sport. Sci, 2021, vol. 9 , pp. 356-362. DOI: https://doi.org/10.13189/saj.2021.090225. 